\title{
Techniques in the Design of Thermomechanical Microactuators
}

Larry L. Howell

Brigham Young University - Provo, Ihowell@byu.edu

Timothy W. McLain

Brigham Young University - Provo, mclain@byu.edu

Michael S. Baker

Brigham Young University - Provo

Christian D. Lott

Brigham Young University - Provo, christian.d.lott@I-3com.com

Follow this and additional works at: https://scholarsarchive.byu.edu/facpub

Part of the Mechanical Engineering Commons

\section{Original Publication Citation}

Howell, L., McLain, T., Baker, M., and Lott, C. Techniques in the Design of Thermomechanical Microactuators, Chapter 7, MEMS/NEMS Handbook, Techniques and Applications, vol. 4, Editor: C.T. Leondes, Springer, pp. 187-200, 2006

\section{BYU ScholarsArchive Citation}

Howell, Larry L.; McLain, Timothy W.; Baker, Michael S.; and Lott, Christian D., "Techniques in the Design of Thermomechanical Microactuators" (2006). Faculty Publications. 1510.

https://scholarsarchive.byu.edu/facpub/1510

This Book Chapter is brought to you for free and open access by BYU ScholarsArchive. It has been accepted for inclusion in Faculty Publications by an authorized administrator of BYU ScholarsArchive. For more information, please contact ellen_amatangelo@byu.edu. 


\title{
Techniques in the Design of Thermomechanical Microactuators
}

\author{
Larry L. Howell ${ }^{1}$, Timothy W. McLain ${ }^{1}$, Michael S. Baker ${ }^{2}$, and \\ Christian D. Lott $^{3}$ \\ ${ }^{1}$ Department of Mechanical Engineering, Brigham Young University \\ ${ }^{2}$ Sandia National Laboratories \\ ${ }^{3}$ L-3 Communications
}

\section{INTRODUCTION}

The purpose of this chapter is to provide fundamental background for the design of thermomechanical microactuators. Actuation has been a particularly challenging aspect of microsystem development. Many actuation approaches used at the macro level, such as hydraulics, pneumatics, electric motors, internal combustion engines and turbines, are either too difficult to fabricate at the micro level or do not work well at that scale. Electrostatic attraction is one approach that has been widely used for actuation of microsystems; however, electrostatic actuators tend to have high voltage requirements and low output force capabilities. While electrostatic actuation is suitable for many applications, some systems require either lower voltages to be compatible with on-chip electronics or higher output forces.

Thermal expansion phenomena are seldom used for actuation at the macro level but can be highly effective as an actuation approach for microsystems. The magnitude of the thermal expansion is small, but approaches for amplifying this expansion can produce relatively large displacements. The following sections provide a background in the basic principles in thermal expansion of microactuators, including methods for amplification. Some examples of thermal actuator designs are described. Linear and nonlinear properties are provided for commonly used micromechanisms. A description of analysis methods is followed by discussion of actuation strategies. 


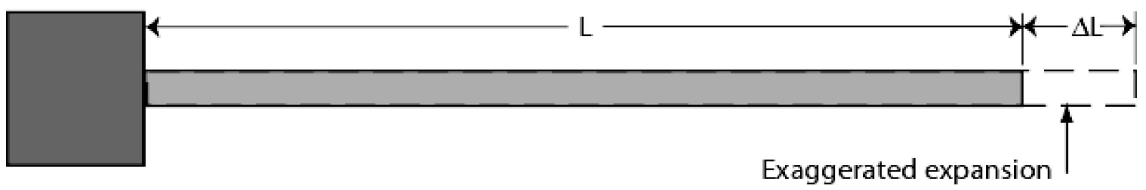

FIGURE 1. Simplified illustration of thermal expansion for a temperature change of $\Delta T$.

\section{THERMAL EXPANSION}

When an object of length $L$ undergoes a change in temperature of $\Delta T$, the change in length, $\Delta L$, can be predicted by the thermal deformation equation:

$$
\Delta L=L \alpha \Delta T
$$

where $\alpha$ is the material's coefficient of thermal expansion. A simplified illustration of thermal expansion is shown in Figure 1. The coefficient of thermal expansion is often treated to be linear over a range of temperatures but it can also be expressed as a function of the temperature, $T$.

The change in dimension due to a change in temperature is often very small. For example, a polycrystalline silicon beam with a length of $L=200 \mu \mathrm{m}$, a temperature change of $\Delta T=500 \mathrm{~K}$ would result in an increase in length of only $\Delta L=0.25 \mu \mathrm{m}$. This small deflection is not adequate for most actuation purposes. Thus, a method of amplifying this displacement is an essential part of a thermal actuator.

Three methods for achieving amplification of thermal expansion are outlined:

- Bimetallic strips

- Pseudo bimorphs

- Geometrically constrained devices

\section{Bimetallic}

Many early thermal microactuators were bimetallic devices that fused together materials with different coefficients of thermal expansion. This is similar to the principle used in many household thermostats. As the temperature increases, one material expands more than the other and the actuator bends to accommodate the different deflections. An example is demonstrated in Figure 2 (Barth, et.al 1994, Kabei, et.al 1997, Riethmuller and Benecke 1998). Challenges associated with bimetallic actuators include somewhat complicated fabrication and the potential for delamination of the layers.

\section{Pseudo Bimorphs}

The bimetallic concept described above heats both materials to the same temperature but exploits their differences in coefficients of thermal expansion. The pseudo bimorph amplification approach uses a single material with a uniform coefficient of thermal expansion, but with different parts experiencing different temperature changes. The primary advantage of this approach is that it is possible to construct an actuator from a single layer of the same material. An example of a well known device in this category is shown in Figure 3 


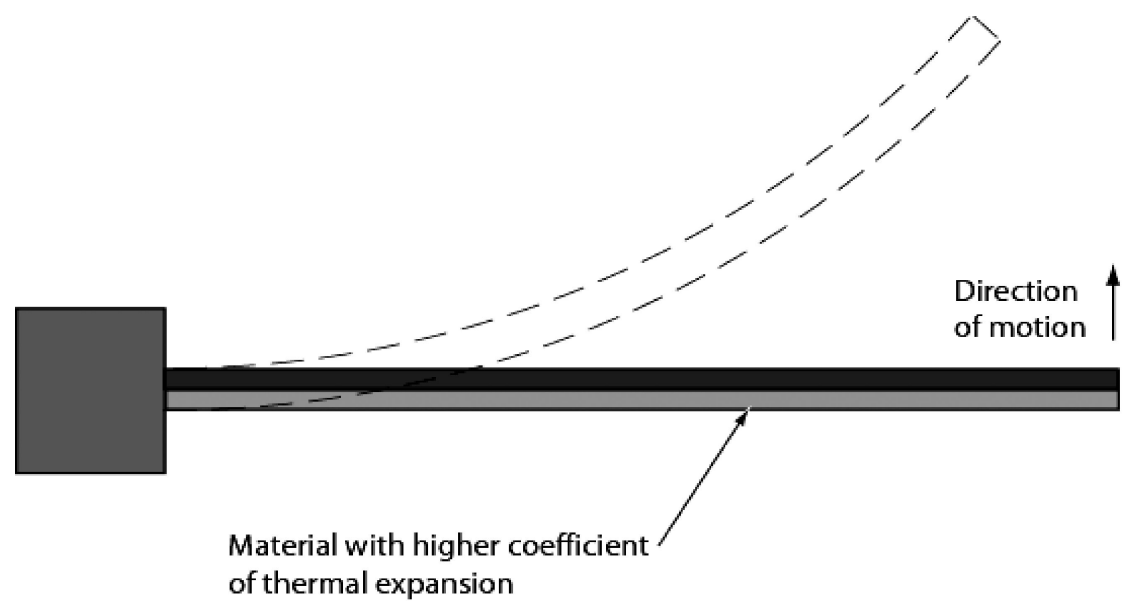

FIGURE 2. Example of bimetallic amplification of thermal expansion.

(Comtois 1998, Huang and Lee, 1999). With this device one leg is made thinner than the other. Voltage is applied and an electric current runs through the legs. The thin leg will have a higher electrical resistance and will heat up more than the wide leg. As the hot leg expands it will cause the actuator to rotate in the direction shown in Figure 3. These devices have also been demonstrated combined together in arrays to obtain higher forces.

\section{Geometric Constraints}

Another approach for amplifying the thermal expansion is to use geometric constraints that force the actuator to move in the desired direction. An example of this type of amplification is the "bent beam" actuator, illustrated in Figure 4 [Que et al., 1999, and Park et al., 2000]. As the thin legs heat up, the expansion causes an amplified deflection in the direction shown.

The Thermomechanical In-plane Microactuator (TIM), illustrated in Figure 5, also exploits geometric constraints [Cragun and Howell, 1999; Lott et al., 2002; Howell and McLain, 2002, Howell and Lyon, 2004]. The TIM is made of a center shuttle connected to thin legs on both sides. The other ends of the legs are anchored to bond pads on the substrate. The legs are fabricated at a slight angle to bias them to move in the desired direction. As

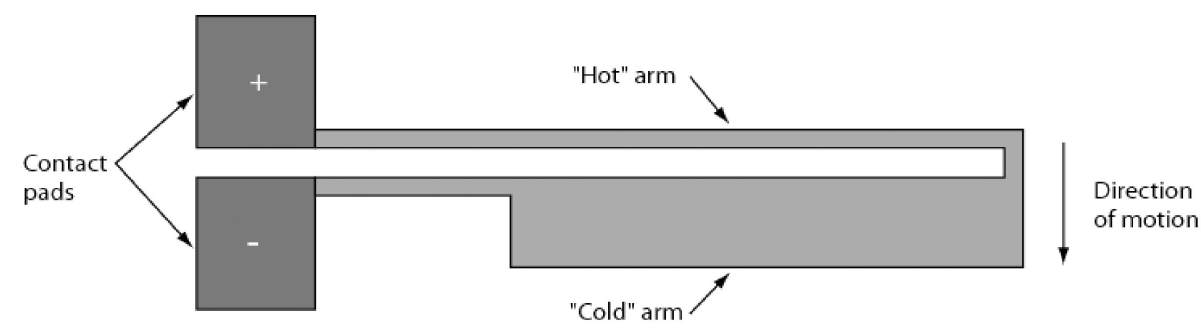

FIGURE 3. An example of a pseudo-bimorph amplification of thermal expansion. 


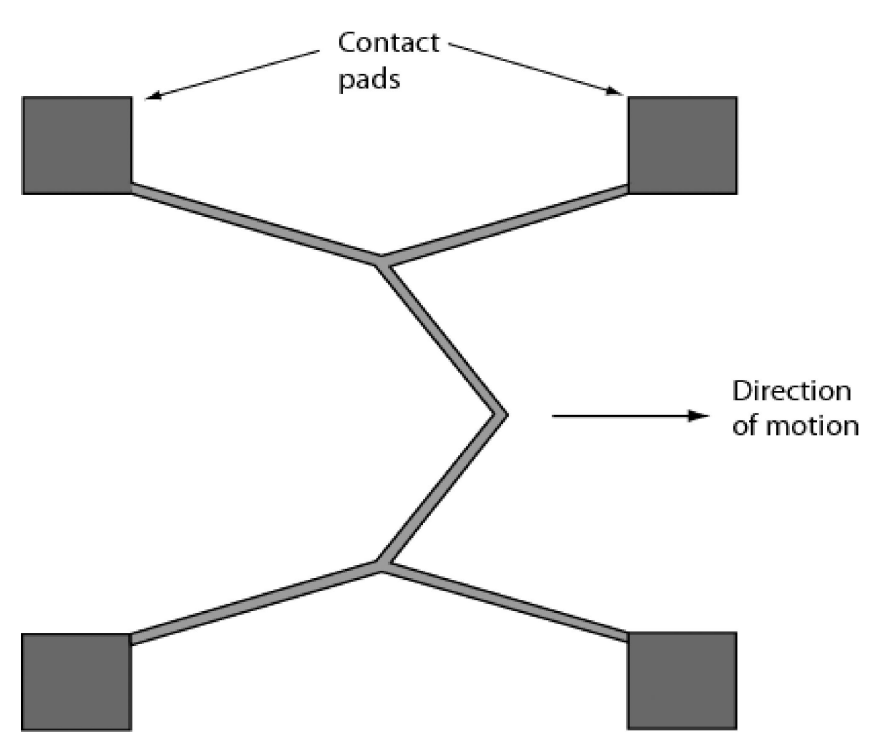

FIGURE 4. An example of geometric constraints used to amplify thermal expansion.

voltage is applied across the bond pads, electric current flows through the thin legs. The legs have a small cross sectional area and thus have a high electrical resistance. This high resistance causes the legs to heat up as the current passes through them. The legs expand but are constrained in their expansion. To accommodate the expansion, the shuttle moves

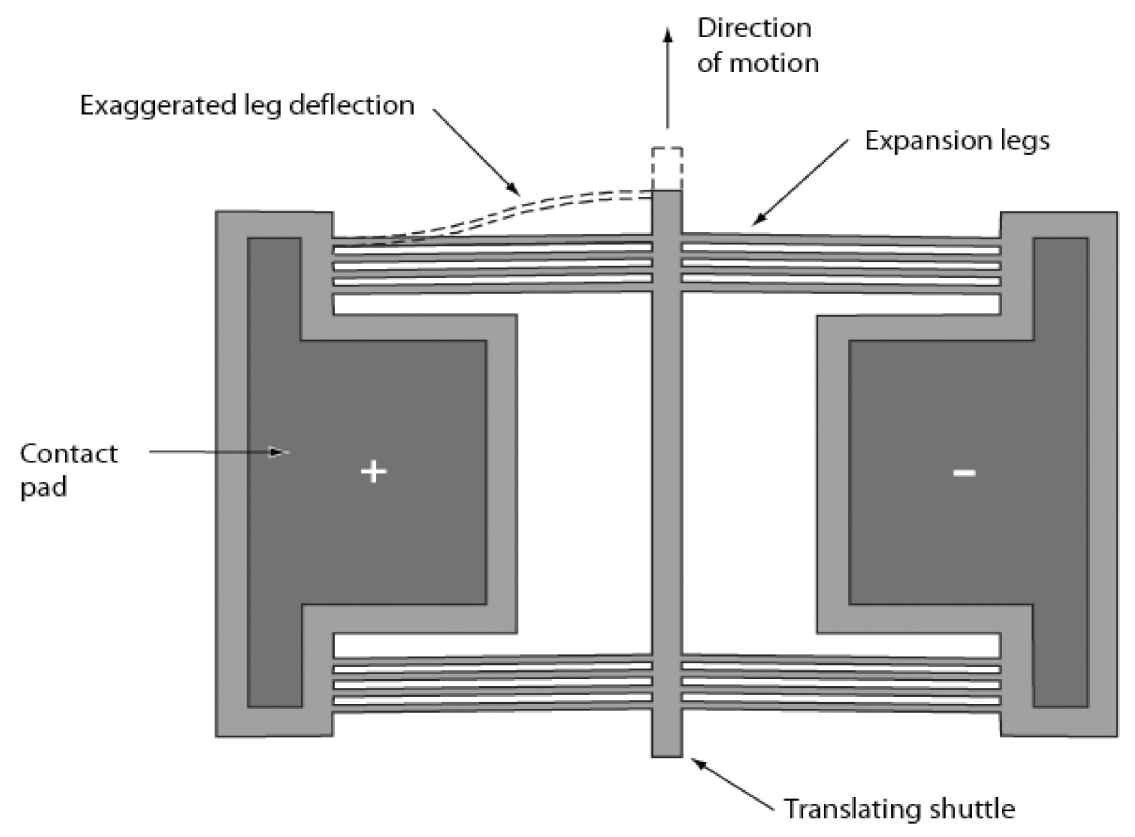

FIGURE 5. The Thermomechanical In-plane Microactuator (TIM). 


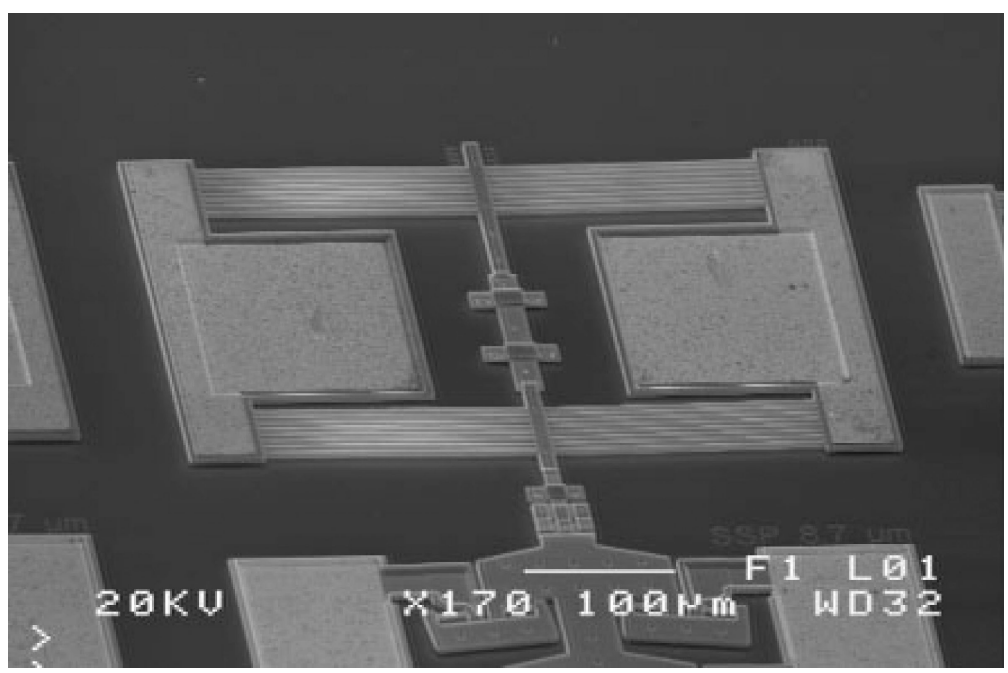

FIGURE 6. A scanning electron micrograph of a TIM.

forward. The displacement of the shuttle is influenced by a number of factors including the material properties, leg length, cross section area, initial biasing angle, and input power. The output force of the actuator is influenced by these same parameters plus the number of legs used. Advantages of this device include its ability to obtain high deflections and large forces, as well as its ability to provide a wide range of output forces by changing the number of legs in the design. A scanning electron micrograph of a TIM is shown in Figure 6.

\section{PROPERTIES}

The performance of thermal actuators is closely linked to their material properties. This section provides some basic material property information that can be used for the modeling and analysis of thermomechanical actuators, with an emphasis on devices constructed of polycrystalline silicon (polysilicon). [Lott et al., 2002]

\section{Thermal Conductivity}

Thermal conductivity is a critical material property for thermal devices. Crystalline materials (well ordered) are of higher conductivity than amorphous materials [Incropera and DeWitt, 1996]. The effect of temperature on crystalline materials can be quite significant. For example, the thermal conductivity of crystalline silicon has been reported to drop from 150 to $22 \mathrm{~W} /(\mathrm{m} \mathrm{K})$ between room temperature and the melting point of silicon $(168 \mathrm{~K})$ [Touloukian, Powell, Ho, and Klemens, 1970]. The temperature also affects the properties of polycrystalline silicon, but there can be a considerable range in these properties due to the variation in grain size for different fabrication processes [Slack, 1964]. Studies have found that constant thermal conductivity between 29 and $34 \mathrm{~W} /(\mathrm{m} \mathrm{K})$ may be used for many polysilicon models [Butler and Bright, 1998; Comtois, Bright, Phipps, 1995; Huang and 
Lee, 1999; Lin and Chiao, 1996; Mastrangelo, 1991]. When a constant value of thermal conductivity of single crystal silicon is desired a value of $150 \mathrm{~W} /(\mathrm{m} \mathrm{K})$ is often used. One study investigating the thermal conductivity of Sandia's large grained polysilicon over a range of temperature from room temperature to $800 \mathrm{~K}$ [Manginell,1997] has resulted in the following expression:

$$
k_{p}(T)=\left[\left(-2.2 \times 10^{-11}\right) \cdot T^{3}+\left(9.0 \times 10^{-8}\right) \cdot T^{2}+\left(-1.0 \times 10^{-5}\right) \cdot T+0.014\right]^{-1}
$$

where $T$ is the temperature in degrees Celsius.

Many thermal devices employ $\mathrm{Si}_{3} \mathrm{~N}_{4}$, and its thermal conductivity may be approximated by a constant of $2.25 \mathrm{~W} /(\mathrm{m} \mathrm{K})$.

Most thermal actuators will operate in an environment of air or similar fluid, and its thermal conductivity has a large influence on the performance of the devices. Thermal conductivity of air is well understood and is found in many texts [Holman, 1997; Incropera and DeWitt, 1996]. A linear fit to tabular values in [Holman, 1997] for the range from room temperature to $1100 \mathrm{~K}$ provides an approximation useful for the range of most thermal actuators. This is

$$
k_{\text {air }}=9.97 \times 10^{-3}+5.89 \times 10^{-5} \mathrm{~T}
$$

A more accurate third order polynomial expression is valid to the melting point of silicon $(1411 \mathrm{C})$ and is

$$
k_{\text {air }}=3.9539 \times 10^{-4}+\left(9.886 \times 10^{-5}\right) T-\left(4.367 \times 10^{-8}\right) T^{2}+\left(1.301 \times 10^{-11}\right) T^{3}
$$

where $T$ is in Kelvin and the thermal conductivity is in $\mathrm{W} /(\mathrm{m} \mathrm{K})$. Many researchers prefer to use the constant value near room temperature of $0.0276 \mathrm{~W} /(\mathrm{m} \mathrm{K})$ for simple approximations.

\section{Resistivity of Polysilicon}

The resistivity of polysilicon is dependent on its dopant concentrations. For electrothermal devices in polysilicon, setting the room temperature resistivity by controlling doping levels is well understood in the IC industry. However, resistivity is less understood at higher temperatures.

The resistivity, $\rho$, is often modeled with a linear relationship using a temperature coefficient of resistance, $\xi$. This relationship can be written as

$$
\rho(T)=\rho_{0}\left[1+\xi\left(T-T_{0}\right)\right]
$$

where $T$ is the temperature, $T_{0}$ the reference temperature, $\rho_{0}$ resistivity at $T_{0}$. This expression has been used by a number of researchers to model the temperature dependence of sensors and microactuators [Butler and Bright, 1998; Huang and Lee, 1999; Lin and Chiao, 1996; Mastrangelo, 1991]. Values of $\xi=1.25 \times 10^{-3} K^{-1}$ and $\rho_{0}=16.92 \times 10^{-6} \Omega \mathrm{m}$ have been reported for one common surface micromachining process (MEMSCAP's Multi-User MEMS Processes, or MUMPs) [Butler and Bright, 1998] and $\xi=1.7 \times 10^{-3} \mathrm{~K}^{-1}$ and $\rho_{0}=$ $20 \times 10^{-6} \Omega \mathrm{m}$ for another (Sandia National Laboratories' SUMMiT V) [Messenger et al., 2004]. At higher temperatures [Greve, 1982] time and temperature dependent dopant segregation at grain boundaries and re-diffusion of dopands into grains have been observed which results in variable resistivity values. 
Specific Heat

The specific heat for silicon is approximated as [Barin, 1993, and Amemiya, Ono, and Kato, 1979]

$$
c=\left(1.976362 \times 10^{-6}\right) T^{3}-\left(3.766786 \times 10^{-3}\right) T^{2}+(2.622954) T+2.149586 \times 10^{2}
$$

between $292 \mathrm{~K}$ and $700 \mathrm{~K}$, and

$$
c=-\left(3.377784 \times 10^{-5}\right) T^{2}+\left(2.388945 \times 10^{-1}\right) T+7.324063 \times 10^{2}
$$

between $701 \mathrm{~K}$ to $1685 \mathrm{~K}$.

The specific heat, $c$, is in units of $\mathrm{J} /(\mathrm{kg} \mathrm{K})$. Isolated measurement of polysilicon and single crystal silicon has suggested that a practical error bound of $5 \%$ on the silicon specific heat is acceptable for polysilicon [Manginell, 1997]. A constant value $705 \mathrm{~J} /(\mathrm{kg} \mathrm{K})$ can be used as a constant value for specific heat when making simplified approximations using polycrystalline silicon.

\section{Coefficient of Thermal Expansion}

The coefficient of thermal expansion is a critical parameter for the analysis of thermal actuators. A curve fit of empirical data for silicon is given by [Okada and Tokumaru,Y., 1984]

$$
\alpha(T)=\left(3.725\left\{1-\exp \left(-5.88 \times 10^{-3}(T-125)\right)\right\}+5.548 \times 10^{-4} T\right) \times 10^{-6}
$$

where $T$ is the absolute temperature from 120 to $1500 \mathrm{~K}$. This expression is for high purity silicon but has been used by many to model the coefficient thermal expansion of polysilicon [Butler and Bright, 1998; Butler, Bright, and Cowan, 1999]. A near room temperature value of $\alpha=2.7 \times 10^{-6}\left(K^{-1}\right)$ is sometimes used as a constant value when making approximations.

\section{Young's Modulus}

Young's modulus is an important parameter in modeling the thermo-mechanical behavior of thermomechanical actuators. The magnitude of the Young's modulus will vary depending on the material and the fabrication process used. MUMPs polysilicon has been measured to have a Young's modulus of $162 \pm 14 \mathrm{GPa}$ [Sharpe et al., 1999].

\section{MODELING}

While thermomechanical microactuators have in many cases been designed through a process of trial and error, it is more effective to develop a model of the actuator and use this model in the design process. As the name implies, a model of a thermal actuator requires the coupling of several different physics to fully capture the relevant effects. These include modeling the electro-thermal response due to joule heating and the thermo-mechanical response due to the temperature increase of the actuator. Because of the coupled nonlinear nature of the actuator, it is difficult to derive a closed-form analytical solution that accurately 


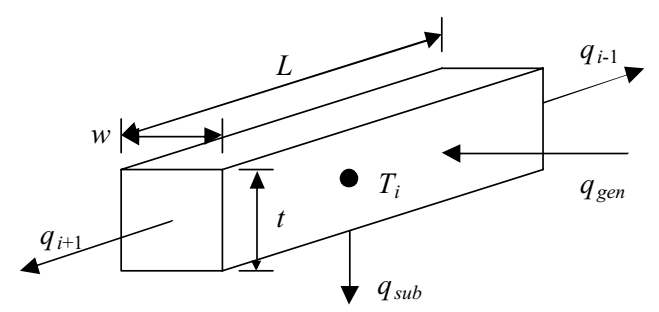

FIGURE 7. Representation of finite-difference element showing relevant heat transfer terms.

models actuator performance. As a result, numeric models have been used with success to predict actuator performance. These models can range from finite-difference approaches to full three-dimensional finite-element analyses [Lott et. al., 2002; Butler, Bright, and Cowan, 1999; Huang and Lee, 1999].

To solve the electro-thermal portion of the thermal actuator problem it is appropriate to use a finite-difference formulation as this method can be applied to a wide variety of actuator topologies and is direct in its implementation. With this approach the actuator beams are divided into a number of serially connected finite-difference elements with a node centered in each element. The temperature of the finite-difference node represents the average temperature of the element [Incropera and DeWitt, 1996]. Heat transfer equations can then be written for each of the elements as illustrated in Figure 7 with a heat transfer term for conduction along the actuator beam to the previous and next elements $\left(q_{i+1}\right.$ and $\left.q_{i-1}\right)$, conduction through the surrounding air into the substrate $\left(q_{s u b}\right)$, and heat generation due to joule heating $\left(q_{g e n}\right)$. Each of these heat transfer terms are defined as

$$
\begin{aligned}
q_{i+1} & =\frac{k_{p} A\left(T_{i}-T_{i+1}\right)}{L} \\
q_{i-1} & =\frac{k_{p} A\left(T_{i}-T_{i-1}\right)}{L} \\
q_{\text {sub }} & =\frac{S k_{a} w L\left(T_{i}-T_{s u b}\right)}{g} \\
q_{\text {gen }} & =\frac{\rho L i^{2}}{A}
\end{aligned}
$$

where $k_{p}$ is the thermal conductivity of the actuator material, $k_{a}$ is the thermal conductivity of the surrounding air (zero if operating in vacuum), $A$ is the cross-sectional area of the actuator beam, $L$ is the distance between finite-difference nodes, $w$ is the beam width in the plane of the substrate, $g$ is the gap between the bottom of the actuator and the substrate, $S$ is a 2-D conduction shape factor derived based on the actuator cross-section and gap, and $i$ is the applied current.

At this small scale, conduction through the surrounding air and into the substrate is a dominant heat loss mechanism; radiation and free convection are negligible and can therefore be ignored [Lott et al., 2002; Hickey et al., 2002]. Particular mention should be made of the shape factor, $S$, in equation (11). This factor accounts for the heat loss from the top and sides of the actuator leg and is defined as the ratio of the total heat loss divided 
by the heat loss from only the bottom surface of the actuator [Incropera and DeWitt, 1996]. Shape factors for any cross-sectional shape can be directly determined using 2D finiteelement heat transfer analyses. For example, a curve fit to FEA results for a rectangular cross section has been given by [Lin and Chiao, 1996] as

$$
S=\frac{t}{w}\left(\frac{2 g}{t}+1\right)+1
$$

With the actuator beams divided into equally spaced finite-difference nodes, a steady-state thermal equilibrium equation can be written at each of the nodes.

$$
q_{i+1}+q_{i-1}+g_{s u b}=q_{g e n}
$$

With $n$ nodes, there will be $n$ equilibrium equations where the only unknowns are the $n$ nodal temperatures. This linear system of equations can then be solved using traditional linear algebra techniques [Moore and Yaqub, 1998]. To account for temperature dependent material properties the solution becomes iterative, with the properties being reevaluated after each solution at the new temperature and the problem re-solved until it converges.

With the electro-thermal problem solved, the temperature profile then becomes the input to the thermo-mechanical analysis. Because thermal actuators typically use beam geometries, this problem can be solved using structural beam elements in a finite-element formulation [Przemieniecki, 1985]. While it is possible to write a custom finite-element code to perform this solution, several commercial finite-element software packages exists that are capable of performing this type of analysis. Examples include ANSYS, Nastran, FEMLAB, and ABAQUS. It is important that a nonlinear solver be used in this step because of the large deflection and stress-stiffening that can occur, as well as to account for temperature dependent material properties. From the finite-element analysis results the actuator displacement, output force, and maximum stresses can be determined.

\section{Case Study: Actuator Design and Model Validation}

A bent-beam style thermal actuator has been fabricated in the Sandia National Laboratories SUMMiT $\mathrm{V}^{\mathrm{TM}}$ surface micromachining process [Sniegowski and de Boer, 2000]. A scanning-electron micrograph of the actuator is shown in Figure 8, with the as-drawn dimensions listed in Table 1 . The length, $L$, is defined as the $x$ distance from the anchor to the center shuttle and the offset, $y$, is the vertical offset defining the angle of the leg. The

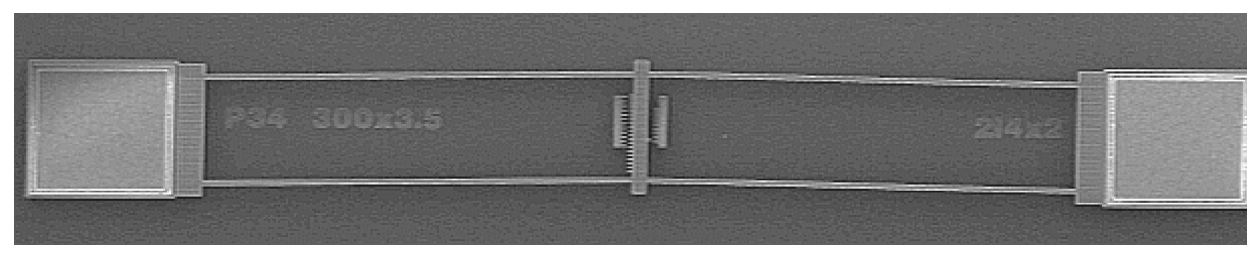

FIGURE 8. SEM image of the SUMMiT $\mathrm{V}^{\mathrm{TM}}$ actuator. 
TABLE 1. Actuator dimensions and cross-sectional properties.

\begin{tabular}{|c|c|c|}
\hline \multicolumn{2}{|c|}{ Actuator Dimensions } & Cross-Sectional Area Description \\
\hline$w 1$ & $4.0 \mu \mathrm{m}$ & \\
\hline$w 2$ & $2.0 \mu \mathrm{m}$ & \\
\hline$t 1$ & $2.5 \mu \mathrm{m}$ & \\
\hline$t 2$ & $2.25 \mu \mathrm{m}$ & \\
\hline$t 3$ & $2.0 \mu \mathrm{m}$ & \\
\hline$L$ & $300 \mu \mathrm{m}$ & \\
\hline$y$ & $3.5 \mu \mathrm{m}$ & \\
\hline
\end{tabular}

cross-section dimensions are labeled in the schematic in Table 1. The I-beam cross-section is produced by using the P1P2 laminate layer and the P3 layer together, and was done to increase the out-of-plane stiffness of the actuator.

The actuator was tested by stepping up the applied current in $1 \mathrm{~mA}$ increments and measuring the displacement and voltage at each step. Current was increased until the actuator failed due to melting of the heated legs. Displacement was recorded using a National Instruments image tracking algorithm, that when used with a $100 \mathrm{X}$ magnification objective, is capable of \pm 0.25 micron displacement resolution. The current source was a Keithley 2400 SMU and the voltage was recorded using a four-point measurement to eliminate any series resistance of the probes and cabling. This measurement allows for the calculation of total actuator resistance, which is a useful metric for model validation.

The actuator performance was modeled using the technique described previously. The conduction shape factor was calculated for this specific cross-section shape using 2D finiteelement analysis (ANSYS) and measured material properties were used where available. The measured and modeled results for total actuator resistance and final displacement are shown in Figures 9 and 10 respectively. The roll-off seen in the measured data beginning at approximately $18-19 \mathrm{~mA}$ is due to excessive heating resulting in permanent deformation and ultimately melting of the actuator.

As can be seen from Figures 9 and 10, a coupled electro-thermal and thermo-mechanical model is capable of accurately predicting the performance of thermal microactuators. To achieve this level of correlation it is necessary to include the effects of temperature on material properties. The validated model can now be used as a design tool to develop thermal actuators that are customized to specific applications. 


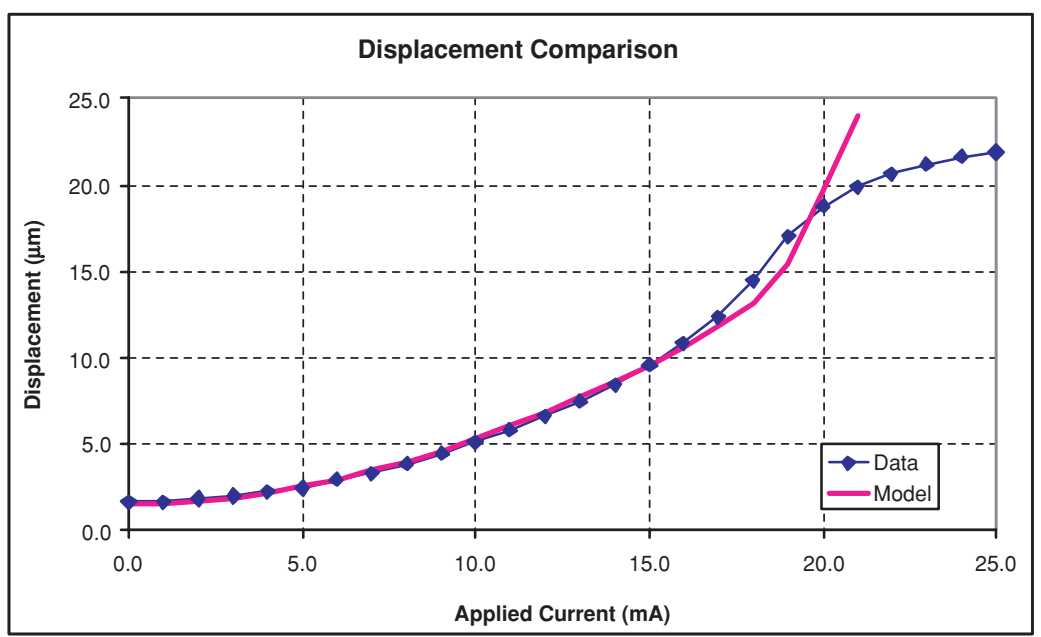

FIGURE 9. Comparison between modeled results and measured data for actuator displacement as a function of the applied current.

\section{STRATEGIES}

There are a number of strategies that can be helpful in the design and implementation of thermomechanical microactuators. A few of these associated with the TIM are presented here, but the general principles may be applied to other devices.

Some basic design guidelines are useful in determining TIM geometry. For example, to achieve increased displacement increase leg length or decrease leg angle. For increased

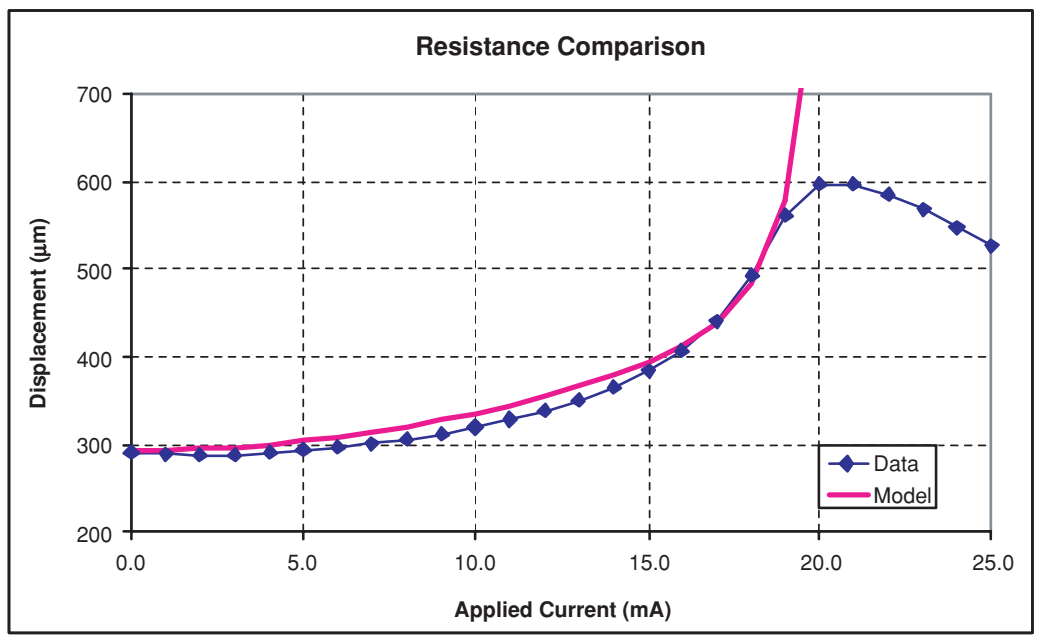

FIGURE 10. Comparison between modeled results and measured data for actuator resistance as a function of applied current. 


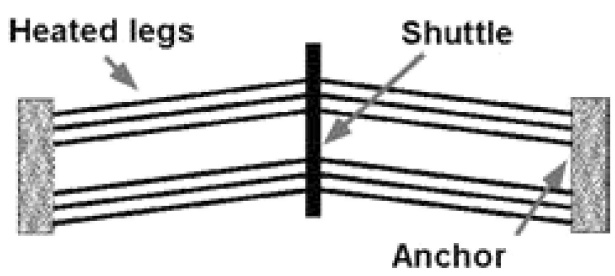

(a)

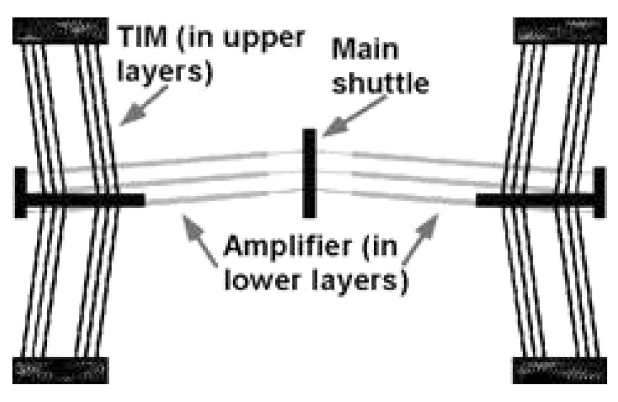

(c)

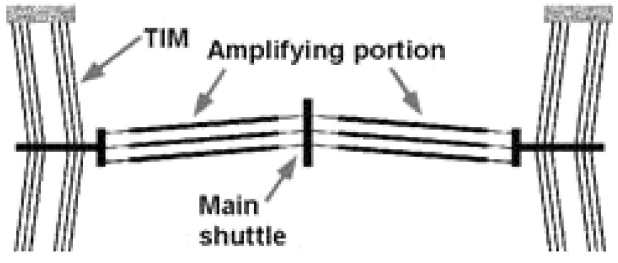

(b)

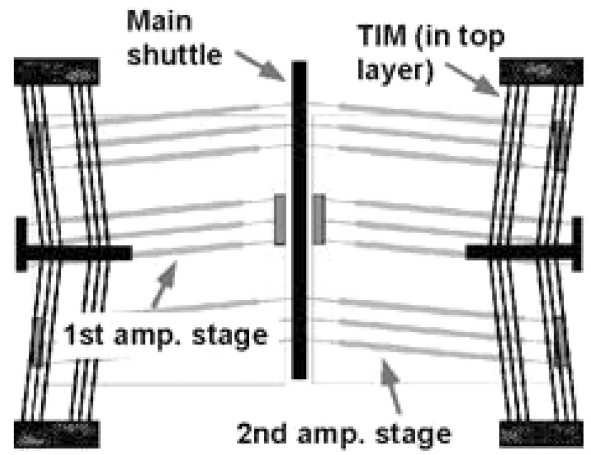

(d)

FIGURE 11. (a) A TIM, (b), an ATIM, (c), (d), StATIMs.

output force, increase cross-sectional area, decrease leg length, increase leg angle, or increase number of legs.

Energy consumption is an issue for some applications. Models and experiments have demonstrated that it is possible to actuate thermal actuators with short-duration, high-voltage pulses [Messenger et al., 2004]. The same displacement may be achieved by an actuator for a long pulse of low voltage, or a shorter pulse with a high voltage. Although the short pulse results in a higher input power, its duration is short and the overall energy needed to achieve the displacement can be significantly smaller with the short pulse. Less energy is lost to the environment, making it more efficient. This is particularly important in applications with on-chip energy sources such as microbatteries [Harb et al., 2002], or in other situations where energy usage or heat generation is a critical issue.

Two basic examples of using geometric constraints to amplify motion were provided earlier. Figure 11 illustrates a successive list of more complex amplification approaches. Figure 11a is the TIM already discussed. Two TIMs can be combined to push on additional amplifying elements to create an amplified thermomechanical in-plane microactuator (ATIM), as illustrated in Figure 11b. This configuration can achieve higher displacements than the TIM, but has a larger footprint. If multiple layers are available, the footprint of the ATIM can be reduced by placing the TIMs and amplifying legs in different layers. This approach leads to the stacked amplified thermomechanical in-plane microactuator, or StATIM [Wilcox and Howell, 2004]. Figure 12 shows an SEM of a StATIM. 


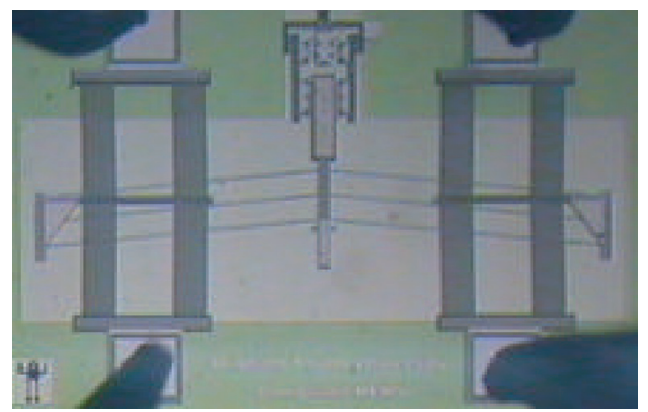

FIGURE 12. Image of a StATIM.

\section{CONCLUSION}

Thermomechanical microactuators provide a means of obtaining comparatively large output forces at the micro level. Their simplicity in design allows them to be easily fabricated. Although the magnitude of thermal expansion is small, there are several approaches for amplifying these deflections to obtain large displacements. The behavior of these actuators can be accurately modeled and the models are valuable in understanding the behavior and in designing devices for new applications.

\section{REFERENCES}

Amemiya, Y., Ono, T., and Kato, K., 1979, "Electrical Trimming of Heavily Doped Polycrystalline Silicon Resistors," IEEE Transaction on Electron Devices, Vol. 26 No. 11, pp. 1738-1742.

Barin, I., 1993, “Thermochemical Data of Pure Substances," VCH, Weinheim.

Barth, P.W., Beatty, C.C., Field, L.A., Baker, J.W., and Gordon, G.B., 1994, "A Robust Normally-Closed Silicon Microvalve," Solid-State Sensor and Actuator Workshop, pp. 248-250.

Butler, J.T., and Bright, V.M., 1998, "Electrothermal and Fabrication Modeling of Polysilicon Thermal Actuators," ASME DSC-MEMS-Vol. 66, pp. 571-576.

Butler, J.T., Bright, V.M., and Cowan, W.D., 1999, "Average Power Control and Positioning of Polysilicon Thermal Actuators," Sensors and Actuators A, Vol. 72, pp. 88-97.

Comtois, J.H., Bright, V.M., Phipps, M.W., 1995, “Thermal microactuators for surface-micromachining processes.” SPIE, Vol. 2642, pp. 10-21.

Comtois, J.H., Michalicek, M.A., and Barron, C.C., 1998, "Electrothermal actuators fabricated in four-level planarized surface micromachined polycrystalline silicon," Sensors and Actuators A, Vol. 70, pp. 23-31.

Cragun, R., and Howell, L.L., "Linear Thermomechanical Microactuators," Microelectromechanical Systems (MEMS), at the 1999 ASME International Mechanical Engineering Congress and Exposition, pp. 181-188, November, 1999.

Greve, D.W., 1982, "Programming Mechanism of Polysilicon Resistor Fuses," IEEE Transaction on Electron Devices, Vol. 29, No. 4, pp. 719-724.

Harb, J.N., LaFollette, R.M., Selfridge, R.H., and Howell, L.L., "Microbatteries for Self-Sustained Hybrid Micropower Supplies," Journal of Power Sources, Vol. 104, No. 1, pp. 46-51, 2002.

Hickey, R., Sameoto, D., Hubbard, T., Kujath, M., "Time and frequency response of two-arm micromachined thermal actuators," Journal of Micromechanics and Microengineering, v. 13, p. 40-46, 2002.

Holman, J.P., 1997, Heat Transfer, 8th Ed., McGraw-Hill.

Howell, L.L., and McLain, T.W., “A Little Push,” Mechanical Engineering, pp. 58-59, October 2002. 
Howell, L.L., and Lyon, S.M., “Thermomechanical In-Plane Microactuator (TIM),” U.S. Patent No. 6,734,597, issued May 11, 2004.

Huang, Q.A., and Lee, N.K.S., 1999, “Analysis and Design of Polysilicon Thermal Flexure Actuator," Journal of Micromechanics and Microengineering, Vol. 9, pp. 64-70.

Incropera, F.P., and DeWitt, D.P., 1996, Introduction to Heat Transfer, 3rd Ed., John Wiley, New York.

Kabei, N., Kosuda, M., Kagamibuchi, H., Tashiro, R., Mizuno, H., Ueda, Y., and Tsuchiya, K., 1997, "ThermalExpansion-Type Microatuator with Paraffin as the Expansive Material," JSME International Journal, Vol. 40, pp. 736-742.

Lin, L., and Chiao, M., 1996, "Electrothermal Responses of Lineshape Microstructures," Sensors and Actuators A, Vol. 55, pp. 35-41.

Lott, C.D., McLain, T.W., Harb, J.N., Howell, L.L., "Thermal Modeling of a Surface-micromachined Lineardisplacement Thermomechanical Microactuator," Sensors \& Actuators: A. Physical, Vol. 101, No. 1-2, pp. 239-250, 2002.

Manginell, R.P., 1997, "Polycrystalline-Silicon Microbridge Combustible Gas Sensor," Ph.D. Dissertation, University of New Mexico.

Mastrangelo, C.H., 1991, “Thermal Applications of Microbridges," Ph.D. Dissertation, University of California at Berkley.

Messenger, R.K., Baker, M.S., McLain, T.W., Howell, L.L., and Harb, J.N., "Modeling the Transient Response of Surface Micromachined Thermal Actuators," submitted for publication in Journal of Micromechanics and Microengineering.

Moore, H.G., and Yaqub, A., A First Course in Linear Algebra with Applications 3rd Edition, Academic Press, 1998.

Okada, Y., and Tokumaru,Y., 1984, "Precise Determination of Lattice Parameter and Thermal Expansion Coefficient of Silicon between 300 and 1500 K," Journal of Applied Physics, Vol. 56, No. 2, pp. 314-320.

Park, J.S., Chu, L.L., Siwapornsathain, E., Oliver, A.D., "Long Throw and Rotary Output Electro-Thermal Actuators Based on Bent-Beam Suspensions," Proceedings of the 13th IEEE International Conference on Micro Electro Mechanical Systems, pp. 680-685, 2000.

Przemieniecki, J.S., Theory of Matrix Structural Analysis, New York, Dover, 1985.

Que, L., Park, J.S., Gianchandani, Y.B., "Bent Beam Electro-Thermal Actuators for High Force Applications," Proceedings of the 12th IEEE International Conference on Micro Electro Mechanical Systems, pp. 31-36, 1999.

Reithmuller, W., Benecke, W., "Thermally Excited Silicon Microactuators," IEEE Transactions on Electrical Devices, Vol. 35, No. 6, pp. 758-762, 1998.

Sharp, W.N., Turner, K.T., and Edwards, R.L., 1999, “Tensile Testing of Polysilicon,” Experimental Mechanics, Vol. 39, No. 3, pp. 162-170.

Slack, G.A., 1964, "Thermal Conductivity of Pure and Impure Silicon, Silicon Carbide, and Diamond," Journal of Applied Physics, Vol. 35, pp. 3460-3466.

Sniegowski, J.J., and de Boer, M.P., "IC-compatible polysililcon surface micromachining," Annu. Rev. Mater. Sci., Vol. 30, pp. 299-333, 2000.

Tai, Y.C., Mastrangelo, C.H., and Muller, R.S., 1988, "Thermal Conductivity of Heavily Doped Low-pressure Chemical Vapor Deposited Polycrystalline Silicon Films," Journal of Applied Physics, Vol. 63, No. 5, pp. 1442-1447.

Touloukian, Y.S., Powell, R.W., Ho, C.Y., and Klemens, P.G., 1970, Thermophysical Properties of Matter, IFI/Plenum, New York.

Wilcox, D.L., and Howell, L.L., "The Stacked Amplified Thermomechanical In-plane Microactuator (StATIM)," Microelectromechanical Systems (MEMS), at the 2004 ASME International Mechanical Engineering Congress and Exposition, IMECE2004-59617. 